\title{
Technical Note: Application of positive matrix factor analysis in heterogeneous kinetics studies utilizing the mixed-phase relative rates technique
}

\author{
Y. Liu ${ }^{1, *}$, S.-M. Li ${ }^{1}$, and J. Liggio ${ }^{1}$ \\ ${ }^{1}$ Air Quality Processes Research Section, Environment Canada, Toronto, M3H 5T4, Canada \\ *now at: Research Center for Eco-Environmental Sciences, Chinese Academy of Sciences, Beijing, 100085, China
}

Correspondence to: J. Liggio (john.liggio@ec.gc.ca)

Received: 4 March 2014 - Published in Atmos. Chem. Phys. Discuss.: 31 March 2014

Revised: 24 July 2014 - Accepted: 28 July 2014 - Published: 8 September 2014

\begin{abstract}
The mixed-phase relative rates approach for determining aerosol particle organic heterogeneous reaction kinetics is often performed utilizing mass spectral tracers as a proxy for particle-phase reactant concentration. However, this approach may be influenced by signal contamination from oxidation products during the experiment. In the current study, the mixed-phase relative rates technique has been improved by combining a positive matrix factor (PMF) analysis with electron ionization aerosol mass spectrometry (unit-mass resolution), thereby removing the influence of $\mathrm{m} / \mathrm{z}$ fragments from reaction products on the reactant signals. To demonstrate the advantages of this approach, the heterogeneous reaction between $\mathrm{OH}$ radicals and citric acid (CA) was investigated using a photochemical flow tube coupled to a compact time-offlight aerosol mass spectrometer (C-ToF-AMS). The measured heterogeneous rate constant $\left(k_{2}\right)$ of citric acid toward $\mathrm{OH}$ was $(3.31 \pm 0.29) \times 10^{-12} \mathrm{~cm}^{3}$ molecule ${ }^{-1} \mathrm{~s}^{-1}$ at $298 \mathrm{~K}$ and $(30 \pm 3) \%$ relative humidity (RH) and was several times greater than the results utilizing individual $\mathrm{m} / \mathrm{z}$ fragments. This phenomenon was further evaluated for particulate-phase organophosphates (triphenyl phosphate (TPhP), tris-1,3-dichloro-2-propyl phosphate (TDCPP) and tris-2-ethylhexyl phosphate (TEHP)), leading to $k_{2}$ values significantly larger than previously reported. The results suggest that heterogeneous kinetics can be significantly underestimated when the structure of the products is highly similar to the reactant and when a non-molecular tracer is measured with a unit-mass resolution aerosol mass spectrometer. The results also suggest that the heterogeneous lifetime of or-
\end{abstract}

ganic aerosol in models can be overestimated due to underestimated $\mathrm{OH}$ uptake coefficients. Finally, a comparison of reported rate constants implies that the heterogeneous oxidation of aerosols will be dependent upon a number of factors related to the reaction system, and that a single rate constant for one system cannot be universally applied under all conditions.

\section{Introduction}

Reaction kinetics data provide key parameters for both air quality and climate models. They are required to compute the trace gas and particulate matter (PM) content of the atmosphere (Kolb et al., 2010) and to evaluate the atmospheric lifetime and fate for individual species. Organic particles make up 10-90\% of the global submicron particle mass in the lower troposphere (Zhang et al., 2011), and are comprised of various reactive organic species, which are subject to atmospheric heterogeneous oxidation. Previous studies have found that heterogeneous reactions with $\mathrm{OH}$, in particular, can lead to an increase in density, cloud condensation nuclei (CCN) activation (George and Abbatt, 2010) and optical extinction (Cappa et al., 2011) of organic particulate matter. Therefore, there is a growing interest in not only understanding the mechanism of PM transformation through heterogeneous reactions including oxidation but also determining the rates at which organic aerosols are chemically transformed in the atmosphere. 
To this end, Donahue et al. (2005) and Hearn and Smith (2006) developed a mixed-phase relative rates technique for measuring organic PM component heterogeneous reaction kinetic rate constants. In this method, the rate constant of the compound of interest is determined from the decrease of its particle-phase relative concentration as a function of oxidant exposure. The oxidant levels are simultaneously estimated via the measured loss of a gas-phase reference compound after applying the known second-order rate constant $\left(k_{2}\right)$ toward the oxidant. In this approach, the rates of chemical change are given by

$$
\begin{aligned}
-\frac{\mathrm{d} c_{A}}{\mathrm{~d} t} & =k_{2, A} c_{A} c_{\mathrm{Ox}}, \\
-\frac{\mathrm{d} c_{R}}{\mathrm{~d} t} & =k_{2, R} c_{R} c_{\mathrm{Ox}},
\end{aligned}
$$

where $c_{A}, c_{R}$ and $c_{\mathrm{Ox}}$ are the particle-phase concentration of the compound of interest $(A)$, the gas-phase concentration of the reference compound $(R)$ and oxidant (molecules $\mathrm{cm}^{-3}$ ), respectively, while $k_{2, A}$ and $k_{2, R}$ are the second-order rate constant of $A$ and $R$ to the oxidant $\left(\mathrm{cm}^{3}\right.$ molecule $\left.{ }^{-1} \mathrm{~s}^{-1}\right)$. A relative rate constant $\left(k_{\mathrm{r}}\right)$ (i.e., particle-phase reaction rate of $A$, relative rate to the gas-phase rate of $R$ ) can be derived by dividing Eq. (1) by Eq. (2). The derivation of $k_{\mathrm{r}}$ provides a means to obtain heterogeneous kinetic data without the need to know the absolute concentration of the oxidant. The differential and integral forms for the relative rates technique are shown as Eqs. (3) and (4),

$$
\begin{aligned}
& \frac{\mathrm{d} c_{A}}{c_{A}}=\frac{k_{2, \mathrm{~A}}}{k_{2, \mathrm{R}}} \frac{\mathrm{d} c_{R}}{c_{R}}=k_{\mathrm{r}} \frac{\mathrm{d} c_{R}}{c_{R}}, \\
& \log \frac{c_{A}}{c_{A, 0}}=k_{\mathrm{r}} \log \frac{c_{R}}{c_{R, 0}},
\end{aligned}
$$

from which the relative rate constant $\left(k_{\mathrm{r}}\right)$ is the slope of the line derived by plotting the logarithmic relative concentration of $A$ against that of $R$ (relative to initial conditions; $\left.c_{A, 0}\right)$. The second-order heterogeneous rate constant of the compound of interest $\left(k_{2, A}\right)$ towards the oxidant may then be calculated using the obtained $k_{\mathrm{r}}$ and the known $k_{2, R}$ (i.e., $\left.k_{2, A}=k_{\mathrm{r}} \times k_{2, R}\right)$.

Using this method, a number of studies have quantified the uptake coefficients of $\mathrm{O}_{3}, \mathrm{OH}, \mathrm{Cl}$ and $\mathrm{NO}_{3}$ on various organic particles, and the corresponding second-order rate constants for the degradation of organic compounds (Hearn and Smith, 2006; George et al., 2007; Lambe et al., 2007; McNeill et al., 2007, 2008; Smith et al., 2009; Kessler et al., 2010, 2012; Renbaum and Smith, 2011; Liu et al., 2012; Sareen et al., 2013).

Although gas chromatograph mass spectrometry (GC-MS) has been widely used in kinetics studies (Weitkamp et al., 2008a, b; Lambe et al., 2009; Isaacman et al., 2012), quantifying the particle-phase loss of an organic compound in such studies often relies upon aerosol mass spectrometry techniques to monitor specific particle-phase reactant ions of in- terest in semi-real-time. Aerosol mass spectrometry instruments utilizing high-resolution detection and soft ionization techniques, such as chemical ionization (aerosol chemical ionization mass spectrometry - CIMS) (Hearn and Smith, 2006; McNeill et al., 2007, 2008; Renbaum and Smith, 2011; Sareen et al., 2013) and vacuum ultraviolet photoionization aerosol time-of-flight mass spectrometer (VUV-A-ToF-MS) (Liu et al., 2012), have been utilized to measure the concentration of the target organic compounds in particles. However, time-of-flight and quadrupole aerosol mass spectrometry (ToF-AMS or Q-AMS) employing electronic ionization $(\mathrm{EI} ; 70 \mathrm{eV}$ ) as an ion source remain the prevalent instruments used in such organic particle experiments. In utilizing this approach, a specific fragment (usually the fastest-decaying ions in the spectrum) is often chosen as a tracer for the particlephase compound of interest. For example, $m / z 297$ has been selected as a tracer for bis(2-ethylhexyl) sebacate (BES) (George et al., 2007), $m / z 71$ for hexacosane (Lambe et al., 2007), $m / z 113$ for squalane (Smith et al., 2009), $m / z 104$ and 144 for erythritol and levoglucosan (Kessler et al., 2010) and $m / z, 152,68$ and 98 for 1,2,3,4-butanetetracarboxylic acid, citric acid and tartaric acid (Kessler et al., 2012), respectively.

However, the use of EI in conjunction with a particle vaporizer in the AMS results in heavy fragmentation for organic compounds due to the high energy associated with the EI source $(70 \mathrm{eV})$ and the high temperature $(\sim 873 \mathrm{~K})$ of the vaporizer (Jayne et al., 2000; Allan et al., 2003). Under such conditions, the tracer $\mathrm{m} / z$ fragment is prone to interferences due to (1) the fragmentation of larger ions and/or molecules and (2) fragments from particle-phase oxidation products. Both can contribute to the tracer $\mathrm{m} / \mathrm{z}$ signal, sometimes leading to an insensitive or nonlinear response of the tracer $m / z$ to the concentration of the target reactant during oxidation. The same may also be true for the $\mathrm{m} / \mathrm{z}$ for the molecular ion, should one exist. In particular, it is true if the structure of the product is highly similar to the reactant and when the tracer is measured with a unit-mass resolution (UMR) aerosol mass spectrometer. Although it is often assumed that the chosen tracer ion does not contribute significantly to the mass spectra of any possible oxidation products or vice versa (Kessler et al., 2010), this is not always the case. In our previous work, we observed that the magnitude of the second-order heterogeneous rate constant $\left(k_{2}\right)$ increases as a function of increasing $\mathrm{m} / \mathrm{z}$ of the fragment chosen as a tracer of the parent molecule (Liu et al., 2014). The same trend has also been observed for the $\mathrm{OH}$ oxidation of ambient biogenic secondary organic aerosol (SOA) (Slowik et al., 2012). This suggests an interference from the fragments selected and points to the necessity of separating the signals of the compound of interest from other compounds (products and/or fragment) for kinetic studies.

In the current study, we improve the mixed-phase relative rates technique used for studies of the heterogeneous oxidation of organic aerosol (OA) using positive matrix 
factorization (PMF) analysis of UMR-AMS derived kinetic data. Heterogeneous kinetics of citric acid (CA) toward $\mathrm{OH}$ oxidation was studied in a photochemical flow tube coupled to an Aerodyne C-ToF-AMS and an Ionicon Analytik highresolution proton transfer reaction mass spectrometer (PTRToF-MS). As it was applied to heterogeneous oxidation of ambient biogenic SOA (Slowik et al., 2012), PMF analysis was used to successfully deconvolve the full mass spectra of the reactant from the potential oxidation products, hence allowing proper accounting of the time evolution of reactant concentrations during photochemical oxidation.

\section{Experimental details}

\subsection{Flow tube experiments}

A detailed schematic representation of the experimental system utilized in this study has been described elsewhere (Liu et al., 2014). Briefly, organic particles (citric acid) were generated via atomization (model 3706, TSI), dried through a diffusion drier and size-selected with a differential mobility analyzer (DMA) (model 3081, TSI). The dried, monodispersed CA particles were introduced into the flow tube reactor and exposed to differing $\mathrm{OH}$ concentrations. $\mathrm{OH}$ radicals were produced by the photolysis of $\mathrm{O}_{3}$ at $254 \mathrm{~nm}$ in the presence of water vapor. $\mathrm{O}_{3}$ was generated by passing zero air through an $\mathrm{O}_{3}$ generator (OG-1, PCI Ozone Corporation). The $\mathrm{O}_{3}$ concentration in the reactor was measured using an $\mathrm{O}_{3}$ monitor (model 205, 2B Technologies) and ranged from 0 to 1000 ppbv. Relative humidity $(\mathrm{RH})$ in the reactor was held constant $(30 \pm 3) \%$ by varying the ratio of wet to dry air used as an air source, and was measured at the exit of the flow tube reactor. The temperature was held constant at $298 \mathrm{~K}$ by circulating a temperature controlled fluid through the outer jacket of the reactor. The residence time in the flow reactor was $52 \mathrm{~s}$. The steady-state $\mathrm{OH}$ exposures were varied from 0 to $\sim 7.0 \times 10^{11}$ molecules $\mathrm{cm}^{-3} \mathrm{~s}$ which was estimated on the basis of the decay of methanol (as a reference compound) from its reaction with $\mathrm{OH}$. The decay of methanol from its reaction with $\mathrm{OH}$ was measured using the PTR-ToF-MS. The $k_{2}$ of methanol, $9.4 \times 10^{-13} \mathrm{~cm}^{3}$ molecules ${ }^{-1} \mathrm{~s}^{-1}$, was used for the $\mathrm{OH}$ exposure calculation (Atkinson and Arey, 2003).

$\mathrm{OH}$ radical reactions were performed in a custom-made reactor consisting of two electro-polished stainless steel cylinders with inner diameter of $7.3 \mathrm{~cm}$. The first stage contained static mixing elements (StaMixCo) to ensure that particles and gas-phase species were well mixed prior to entering the reaction region (second stage). Fluid dynamics simulations of the flow tube confirmed that particles and gas-phase species were well mixed in the reactor, with a uniform initial velocity profile. The size and composition of the particles exiting the reactor were measured by a scanning mobility particle sizer (SMPS, TSI) and an Aerodyne C-ToF-AMS (Drewnick et al., 2005).
Control experiments demonstrated that neither $\mathrm{O}_{3}$ nor $254 \mathrm{~nm}$ light exposure lead to the decomposition of $\mathrm{CA}$. Analytic grade CA (EM, Germany) was used as received. 18.2 $\mathrm{M} \Omega$ water was used as solvent.

\subsection{PMF analysis and kinetics calculation}

Positive matrix factor is a multivariate factor analysis tool that decomposes a matrix of speciated sample data into two matrices, namely, factor contributions and factor profiles (Paatero and Tapper, 1994), such that

$x_{i j}=\sum_{p} g_{i p} f_{p j}+e_{i j}$,

where $i$ and $j$ refer to row and column indices in the matrix, respectively, $p$ is the number of factors in the solution, $x_{i j}$ is an element of the $m \times n$ matrix $\mathbf{X}$ of measured data elements to be fit and $e_{i j}$ is the residual. Results are constrained so that no sample can have a negative source contribution. The PMF solution minimizes the object function $Q$ (Eq. 6), based upon the uncertainties $(u)$ (Norris and Vedantham, 2008).

$Q=\sum_{i=1}^{n} \sum_{j=1}^{m}\left(\frac{e_{i j}}{u_{i j}}\right)^{2}$

The ability of PMF to separate the signals of a multicomponent matrix has been well established. Positive matrix factor analysis has been widely used for source apportionment of ambient particles in field measurements (Song et al., 2006; Yuan et al., 2006; Viana et al., 2008; Ulbrich et al., 2009; Liggio et al., 2010; Schwartz et al., 2010). Three secondary organic aerosol factors (SOA1, SOA2, SOA3) have been identified for $\mathrm{OH}$-initiated oxidation of laboratory SOA (George and Abbatt, 2010). Similarly, SOA factors have also been successfully isolated in $\mathrm{OH}$ oxidation of ambient biogenic SOA (Slowik et al., 2012). Therefore, the use of PMF for separating the reactants from the products in laboratory studies aimed at using the relative rates method for heterogeneous kinetic studies is a reasonable approach.

The AMS data for CA oxidation from all experiments combined were used as input into the PMF Evaluation Toolkit (PET) v2.05 (Paatero, 1997; Paatero and Tapper, 1994; Ulbrich et al., 2009) to separate the signals of CA and the corresponding oxidation products. In the AMS data, the $m$ rows of $\mathbf{X}$ are ensemble average mass spectra (MS) of typically tens of thousands of particles measured over each averaging period (typically $2 \mathrm{~min}$ ) and the $n$ columns of $\mathbf{X}$ are the time series (TS) of each $m / z$ sampled.

Positive matrix factor analyses were done in the robust mode. The default convergence criteria were not modified. The $Q$ values as a function of FPEAK from -1 to +1 were examined (Reff et al., 2007). For the variables with signalto-noise ratios (SNRs) of less than 0.2 ("bad" variables) and down weight variables with SNRs between 0.2 and 2 ("weak" variables), their error estimates were increased by a factor 
of 10 and 3, respectively, as recommended by Paatero and Hopke (2003). In this study, the SNRs of all $m / z$ fragments are larger than 0.2 . The error values for $m / z$ 44, 18, 17 and 16 were multiplied by $\sqrt{(4)}$.

The extracted factor profiles (mass spectra for CA and the oxidation products) were compared with the National Institute of Standards and Technology (NIST) mass spectrum of pure CA and that measured with the C-ToF-AMS directly via atomization. The temporal concentration profiles (factor contributions) of CA were further confirmed via comparison to the known experimental conditions used for kinetics calculations (i.e., zero $\mathrm{OH}$ exposure should result in a $\mathrm{CA}$ factor contribution of $100 \%$ ). For comparison with the PMF results, the kinetic rate constants $\left(k_{\mathrm{r}}\right)$ were also calculated using specific individual tracers of CA at $m / z$ 87, 129 and 147, separately. The $k_{\mathrm{r}}$ of CA toward methanol was calculated according to Eq. (4). The $k_{2}$ of CA was further calculated with the known $k_{2}$ of methanol and $k_{\mathrm{r}}$.

The reactive uptake coefficient of $\mathrm{OH}\left(\gamma_{\mathrm{OH}}\right)$ with $\mathrm{CA}$ was calculated using the following formulation (Kessler et al., 2010, 2012; Worsnop et al., 2002; Liu et al., 2012):

$\gamma_{\mathrm{OH}}=\frac{2 D_{\mathrm{p}} \rho_{\mathrm{CA}} \mathrm{N}_{A}}{3 v_{\mathrm{OH}} \mathrm{M}_{\mathrm{CA}}} \varphi k_{2}$,

where $D_{\mathrm{p}}$ is the surface-weighted average particle diameter of unreacted particles $(\mathrm{cm}), \rho_{\mathrm{CA}}$ is the density of CA $\left(\mathrm{g} \mathrm{cm}^{-3}\right), N_{A}$ is Avogadro's number, $v_{\mathrm{OH}}$ is the average speed of $\mathrm{OH}$ radicals in the gas phase $\left(\mathrm{cm} \mathrm{s}^{-1}\right), \mathrm{M}_{\mathrm{CA}}$ is the molecular weight of $\mathrm{CA}\left(\mathrm{g} \mathrm{mol}^{-1}\right)$ and $\varphi$ is a correction factor for diffusion of $\mathrm{OH}$ from the gas phase to particle phase.

\section{Results}

\subsection{PMF analysis of AMS data}

To ensure that oxidation of CA in particles does not result in a PTR-ToF-MS response for methanol in the gas phase (thus compromising the $\mathrm{OH}$ radical reference measurement), the oxidation of pure CA was performed in the absence of methanol, with no gas-phase methanol signal detected by the PTR-ToF-MS. The mass concentration of the OA measured with the AMS during oxidation is shown in Fig. 1a, which was constant. The results of Fig. 1a demonstrate that the aerosol source is adequately stable for kinetic studies to be performed.

A two-factor solution from the PMF analysis accounts for $99.98 \%$ of the variance of the data. When the number of factors is greater than 2, none of the obtained factors resembles that of pure CA, whose contribution should be approximately $100 \%$ when $\mathrm{OH}$ is absent in the reactor. Figures $1 \mathrm{~b}$ and c present the temporal variations of the typical two-factor PMF solution of AMS data when CA is exposed to varying $\mathrm{OH}$ concentrations. The error bars indicate the rotational uncertainty in the PMF analysis. Three independent experiments were performed to test the response of CA signal to

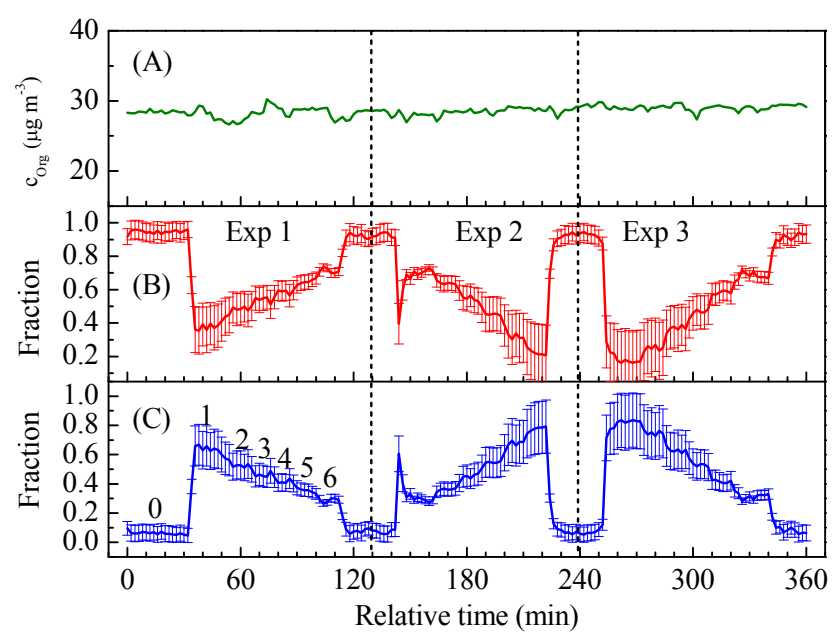

Figure 1. Changes in (a) total organic mass concentration, (b) the fraction of unreacted citric acid derived by PMF and (c) products of citric acid oxidized by $\mathrm{OH}$ derived by $\mathrm{PMF}$, as a function of relative experimental time. The values 1-6 represent a step-wise $\mathrm{O}_{3}$ concentration decrease, corresponding to decreased $\mathrm{OH}$ exposure; 0 represents an $\mathrm{O}_{3}$ concentration of zero. Experimental conditions are $D_{\mathrm{m}}: 200 \mathrm{~nm}, \mathrm{RH}: 30 \pm 3 \%, T: 298 \mathrm{~K}$.

$\mathrm{OH}$ exposure (determined by $\mathrm{O}_{3}$ concentration). In the first and the third experiments, $\mathrm{OH}$ exposure was stepped downwards (high to low $\mathrm{OH}$ ) by changing the power of $\mathrm{O}_{3}$ generator with the same flow rate and $\mathrm{RH}$, while the inverse sequence was performed in the second experiment.

As demonstrated in Fig. $1 \mathrm{~b}$ and $\mathrm{c}$, in the absence of OH radical (labeled "0"), factor 1 (Fig. 1b) accounts for $(94.7 \pm 0.9) \%$ of the OA mass, while factor 2 (Fig. 1c) contributes $(6.2 \pm 0.7) \%$ of the OA. This is consistent with the experimental conditions of zero $\mathrm{OH}$ radicals (i.e., no oxidation), and suggests that factor 1 should be assigned to the citric acid reactant. Impurities in the CA or the water used to atomize CA likely contributed to factor 2 . When $\mathrm{OH}$ exposure was decreased in a step-wise manner in the first and the third experiment (Fig. 1b), the extracted factor representative of CA (factor 1) increased synchronously, and is accompanied with a decrease in factor 2 . Therefore, factor 2 is interpreted as the $\mathrm{OH}$ oxidation products of $\mathrm{CA}$. This is consistent with the second experiment, where the inverse trend was observed with a step-wise $\mathrm{OH}$ exposure increase. Based upon this evidence, we conclude that changes in the time series of factors 1 and 2 extracted by PMF are consistent with the expected response to $\mathrm{OH}$ exposures that, namely, higher $\mathrm{OH}$ exposure resulted in a decrease in CA (factor 1) and an increase in the oxidation products (factor 2).

The factor profiles (i.e., mass spectra) extracted by PMF analysis are shown in Fig. 2. The main fragments of CA including $m / z$ values $129\left(\mathrm{C}_{5} \mathrm{H}_{5} \mathrm{O}_{4}^{+}\right)$and $87\left(\mathrm{C}_{3} \mathrm{H}_{3} \mathrm{O}_{3}^{+}\right)$are present in factor 1 (Fig. 2a). These fragments are in good agreement with the NIST mass spectra of pure CA and the 


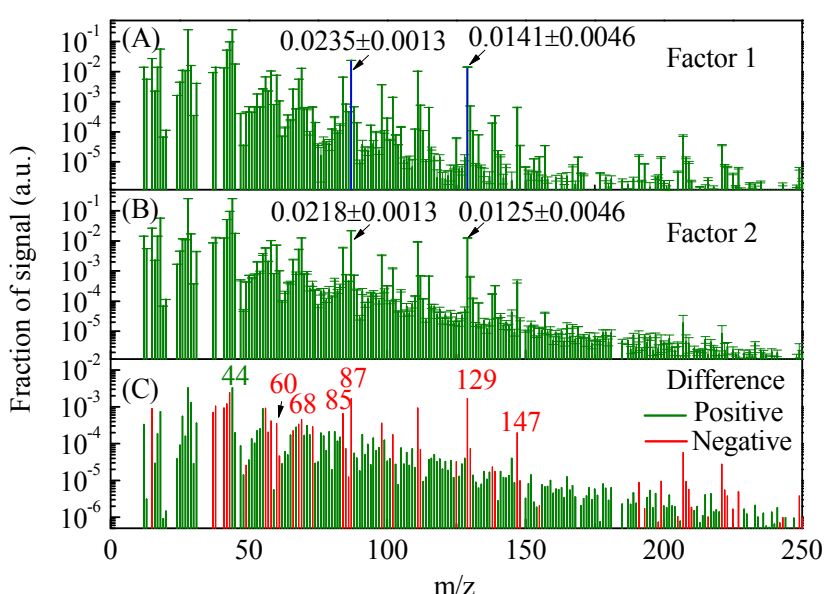

Figure 2. Normalized mass spectra of (a) citric acid (PMF factor 1), (b) citric acid oxidation products (PMF factor 2) and (c) the difference mass spectrum (factor 2-factor 1). The numbers in the upper two rows are the intensities of $m / z 87$ and 129, while negative values are shown in the bottom row. The red and green lines indicate a negative and positive value, respectively.

mass spectra of pure CA particles measured with the C-ToFAMS (Fig. 3). Figure 4 further compared the normalized mass spectra of factor 1 and pure CA directly measured with the C-ToF-AMS. The relative intensities for all ions of pure $\mathrm{CA}$ are linearly correlated with that of factor 1 with a slope of 0.985 and $R$ of 0.9999 . This further confirmed that factor 1 should be assigned to unreacted CA. Figure $2 \mathrm{c}$ shows the difference mass spectra (factor 2-factor 1). Consumption of $m / z$ values $147\left(\mathrm{C}_{5} \mathrm{H}_{7} \mathrm{O}_{5}^{+}\right), 129,87,85\left(\mathrm{C}_{4} \mathrm{H}_{5} \mathrm{O}_{2}^{+}\right)$ and $60\left(\mathrm{C}_{2} \mathrm{H}_{4} \mathrm{O}_{2}^{+}\right)$can be observed, which is consistent with the assignment that factor 2 belongs to oxidation products of CA. However, small changes in the relative intensities of these peaks suggest that the structures of the oxidation products of CA are likely similar to that of CA. For example, as shown in Fig. 2a and b, the intensity of $m / z, 129$ and 87 in factor 2 are $0.0125 \pm 0.0046$ and $0.0218 \pm 0.0013$ compared to $0.0141 \pm 0.0046$ and $0.0235 \pm 0.0013$ in factor 1 .

The changes of the relative concentrations of gas-phase methanol and particle-phase CA are shown in Fig. 5. The signal of CA extracted by PMF analysis also responded to $\mathrm{OH}$ exposure as expected, when methanol was present in the gas phase, which is similar to that of Fig. 1. The relative intensities of the typical tracers of CA at $m / z$ 87, 129 and 147 are shown in Fig. 5c. As shown in Fig. 5b and c, the drop in the PMF product factor is substantially greater than that of any of the individual ions. In addition, the consumption of the smaller tracer $(m / z 87)$ is substantially lower than that of the larger ones $(m / z$ values 129 and 147). For example, the maximum consumption of CA extracted with PMF analysis is approximately $80 \%$, in comparison to $\sim 30, \sim 10$ and $5 \%$ for $m / z$ values 147,129 and 87 , respectively. These results support the small differences in the mass spectra between the

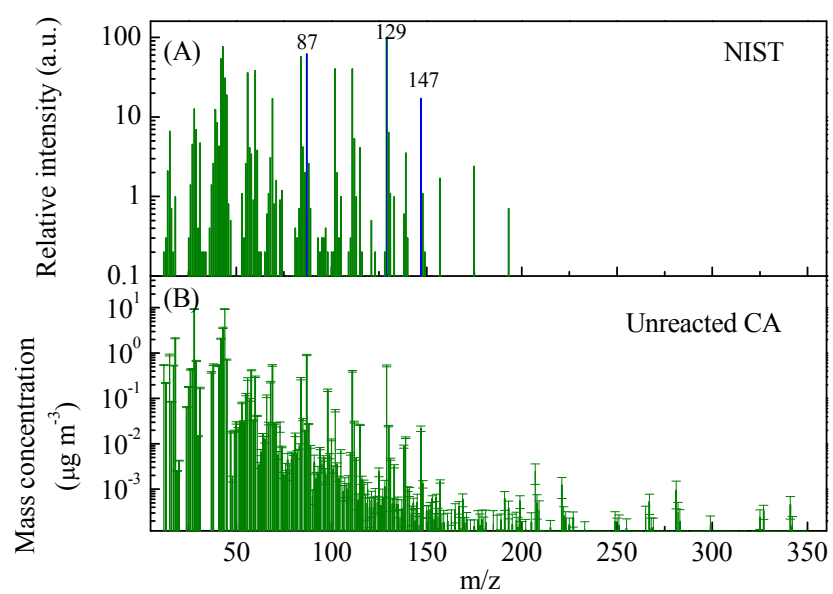

Figure 3. Mass spectra (a) of CA from NIST database, (b) of pure CA measured with the C-ToF-AMS.

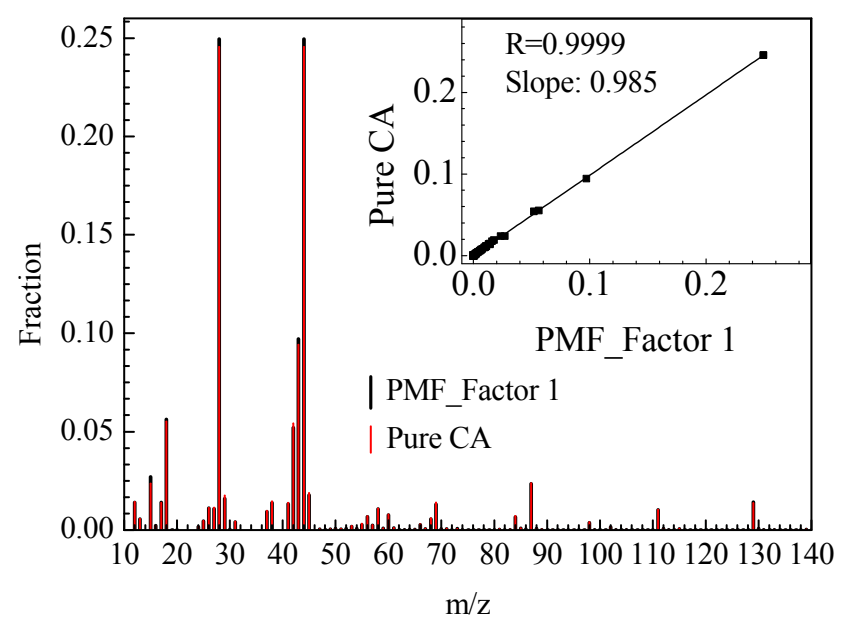

Figure 4. Comparison between the mass spectra of factor 1 from PMF analysis and pure CA directly measured by the C-ToF-AMS. The inset graph is the correlation of their corresponding signal intensities.

unreacted CA and its oxidation products as shown in Fig. 2. Furthermore, it suggests that the measured loss of these fragments, which were supposedly only derived from CA, had in fact contributions from the fragmentation of the products of CA oxidation. This ultimately would lead to an underestimation of the second-order heterogeneous rate constant (or $\mathrm{OH}$ uptake coefficients) if these fragments were chosen as the proxies for the particle-phase concentration of CA. In particular, the difference between the PMF-factor decay rate and the marker-ion decay rate is mathematically possible only when the two factors (reactants and products) are extremely similar. 


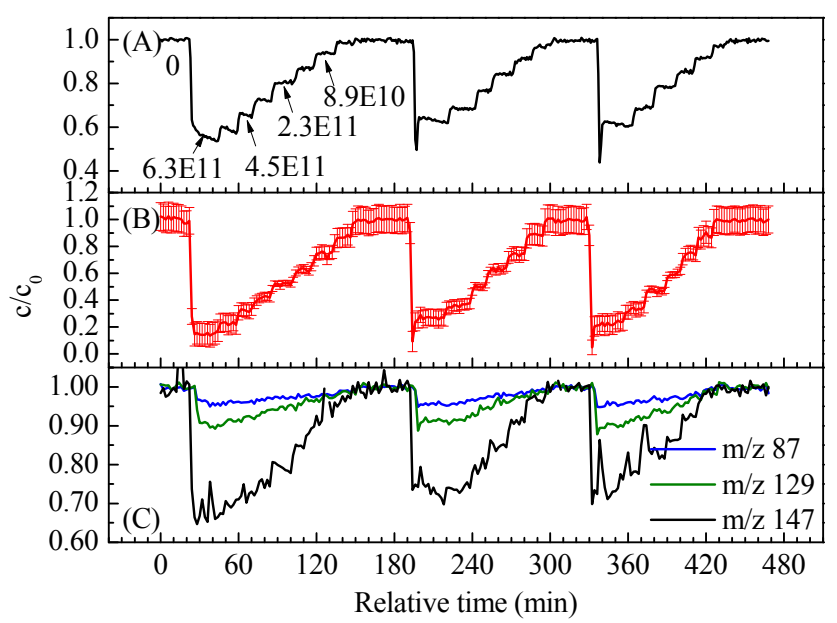

Figure 5. Changes in the relative concentration of (a) methanol, (b) citric acid extracted with PMF analysis and (c) specific tracers measured with the AMS during the $\mathrm{OH}$-initiated oxidation of citric acid. Experimental conditions are $D_{\mathrm{m}}: 140 \mathrm{~nm}, \mathrm{RH}: 30 \pm 3 \%, T$ : $298 \mathrm{~K}$. The values in the top row represent the $\mathrm{OH}$ exposures.

\subsection{Reaction kinetics}

The saturation vapor pressure of CA at $298 \mathrm{~K}$ is $1.6 \times 10^{-7} \mathrm{~Pa}$ (Huisman et al., 2013); thus, $99.9 \%$ of $\mathrm{CA}$ should be present in the particle phase under the current experimental conditions according to a partition model (Kroll and Seinfeld, 2008; Pankow, 1994). Although new particle formation was observed with a condensation particle counter (CPC) in the experiments (at the exit of the reactor), it has no influence on the measured mass concentration of OA due to the small particle size of the new particles. This is well supported by the constant mass concentration of OA measured with the AMS during oxidation experiments (Fig. 1a). In addition, as pointed out in our previous work (Liu et al., 2014), evaporation of CA from particles could potentially contribute to the decreases in particle-phase CA concentration observed as a function of $\mathrm{OH}$ exposure. If $\mathrm{CA}$ evaporation occured, the derived reaction rates will be overestimated using either the present approach or the simpler method of using single fragments. The evaporation of $\mathrm{CA}$ from the particle phase under these experimental conditions from control experiments is less than $0.005 \%$ based upon an evaporation model (Jacobson, 2005). This implies that the observed changes in CA concentration in the particle phase were due to the particlephase reaction.

The relative rates (relative to initial conditions) for $\mathrm{CA}$ and methanol in these experiments are shown in Fig. 6. The logarithmic $c / c_{0}$ of CA both measured with the tracers and extracted with PMF analysis linearly correlated to that of methanol with $R^{2}>0.95$. The derived relative rate constant based upon PMF analysis is $3.01 \pm 0.27$ while it is $0.72 \pm 0.05$ and $0.22 \pm 0.01$ for $\mathrm{m} / \mathrm{z}$ values 147 and 129 , respectively. Applying the $k_{2}$ value of methanol to-

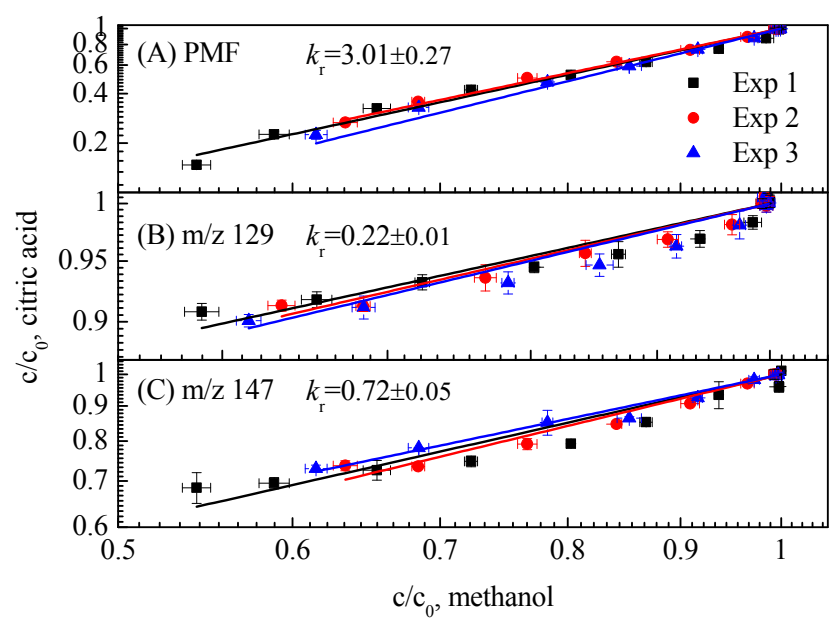

Figure 6. Relative concentration of citric acid $\left(c / c_{0}\right)$ as a function of the relative concentration of methanol based upon (a) PMF analysis, (b) $m / z=129$ and (c) $m / z$ 147. Experimental conditions are $D_{\mathrm{m}}: 140 \mathrm{~nm}, \mathrm{RH}: 30 \pm 3 \%, T: 298 \mathrm{~K}$.

wards $\mathrm{OH}$ of $9.4 \times 10^{-13} \mathrm{~cm}^{3}$ molecules ${ }^{-1} \mathrm{~s}^{-1}$ at $298 \mathrm{~K}$ (Atkinson and Arey, 2003), the $k_{2}$ of CA is calculated as $(2.83 \pm 0.25) \times 10^{-12}$ using the PMF approach, or $(6.77 \pm 0.47) \times 10^{-13}$ using the single tracer at $\mathrm{m} / \mathrm{z} 147$ and $(2.02 \pm 0.01) \times 10^{-13} \mathrm{~cm}^{3}$ molecules ${ }^{-1} \mathrm{~s}^{-1}$ using the single tracer at $m / z, 129$, respectively. The reaction between methanol and $\mathrm{OH}$ radicals occurs in the gas phase, while for the CA oxidation it occurs in the particle phase. Thus, it is necessary to correct for $\mathrm{OH}$ diffusion from the bulk gas phase to the particle phase. Applying a diffusion correction utilizing a previously developed empirical formula (Fuchs and Sutugin, 1970; Worsnop et al., 2002; Widmann and Davis, $1997)$, the diffusion-corrected $k_{2}$ is $(3.31 \pm 0.29) \times 10^{-12}$ using the PMF approach and $(7.92 \pm 0.55) \times 10^{-13}$ and $(2.36 \pm 0.01) \times 10^{-13} \mathrm{~cm}^{3}$ molecules ${ }^{-1} \mathrm{~s}^{-1}$ using single tracers at $m / z \quad 147$ and 129, respectively. The diffusioncorrected $\gamma_{\mathrm{OH}}$ is calculated as $2.74 \pm 0.24$ using the PMF approach and $0.66 \pm 0.05$ and $0.20 \pm 0.01$ using single tracers at $m / z 147$ and 129, respectively. The $\gamma_{\mathrm{OH}}$ values for a number of different organic particles have previously been measured and are in the range of 0.3-2.0 (Kessler et al., 2010; George et al., 2007; Hearn and Smith, 2006; Lambe et al., 2007; Smith et al., 2009; Kessler et al., 2012). As pointed out by Hearn and Smith (2006), the large $\gamma$ implies that secondary radical reactions within the particles could play a significant role in heterogeneous chemistry, particularly since gaseous citric acid in these studies is insignificant.

It should be pointed out that oxidant diffusion in the particle phase should lead to a concentration gradient of oxidant and a negative impact on reaction kinetics (Donahue et al., 2005). However, as shown in Fig. 6, this effect is negligible under the current experimental conditions. Based upon the measured $c / c_{0}$ and the initial diameter of the CA 
particles, the maximum $\mathrm{OH}$ diffusion depth is approximately $25 \mathrm{~nm}$. Given the residence time $(\tau)$ in this study $(52 \mathrm{~s})$, a significant $\mathrm{OH}$ concentration gradient will exist in the particle phase if the $D_{\mathrm{OH}}$ in CA particles is smaller than $1.2 \times 10^{-17} \mathrm{~m}^{2} \mathrm{~s}^{-1}\left(D=l^{2} / \tau\right)$ (Donahue et al., 2005). At the present time, the $D_{\mathrm{OH}}$ in CA particles is unavailable. However, Price et al. (2014) have reported the diffusion of $\mathrm{D}_{2} \mathrm{O}$ in several organics (sucrose and levoglucosan) to be larger than $\sim 1 \times 10^{-16} \mathrm{~m}^{2} \mathrm{~s}^{-1}$ even under dry conditions. This implies that a gradient in $\mathrm{OH}$ concentration in the CA particles is negligible under the current conditions.

\section{Discussion}

Kessler et al. (2012) have reported the $k_{2}$ of $\mathrm{CA}$ toward $\mathrm{OH}$ to be $(4.3 \pm 0.8) \times 10^{-13} \mathrm{~cm}^{3}$ molecule $\mathrm{s}^{-1} \mathrm{~s}^{-1}$ at $308 \mathrm{~K}$ and $30 \%$ RH with an Aerodyne HR-AMS. In their work, the diameter of particles and $\mathrm{RH}$ were equivalent to the current work, while their experimental temperature was $10 \mathrm{~K}$ higher. In addition, an $\mathrm{m} / \mathrm{z}$ fragment of 68 was used as a tracer for $\mathrm{CA}$ in their work to derive the heterogeneous rate constant. Conversely, no significant consumption of $m / z 68$ was observed in the current study. The lack of an $\mathrm{m} / \mathrm{z} 68$ fragment consumption here may be explained by the choice of reaction conditions. In the work of Kessler et al. (2012) OH concentration exposure $\left(0-7 \times 10^{12}\right.$ molecules $\left.\mathrm{cm}^{-3} \mathrm{~s}\right)$ was approximately an order of magnitude higher than that reported here. Recent evidence suggests that the product distribution during OA oxidation greatly depends upon $\mathrm{OH}$ exposure levels (Wilson et al., 2012). Hence, it is possible that more oxidized products were formed via multi-generational chemistry at high $\mathrm{OH}$, which may have less of an influence on the signal of the chosen tracer $(\mathrm{m} / \mathrm{z} 68)$, and result in product AMS spectra which are significantly different than that of the reactant, thus mitigating the use of PMF (which was not the case here). In studies of the $\mathrm{OH}$ oxidation of squalane (Sq) (Smith et al., 2009; Wilson et al., 2012), the first generation product $(\mathrm{SqO})$ was the primary contributor to the products when the $\mathrm{OH}$ exposure was the same as the highest $\mathrm{OH}$ level in the current study $\left(7.0 \times 10^{11}\right.$ molecules $\left.\mathrm{cm}^{-3} \mathrm{~s}\right)$, while higher generation products were predominant at $\mathrm{OH}$ exposures greater than $\sim 2 \times 10^{12}$ molecules $\mathrm{cm}^{-3} \mathrm{~s}$. Although not directly comparable, it is reasonable to assume that lower $\mathrm{OH}$ exposure in the current work should lead primarily to the first generation products, which are highly similar to CA. However, the formation of multi-generation products cannot be completely ruled out. Secondly, the difference in $\mathrm{OA}$ and oxidant concentrations as well as timescale may also have an influence on the product distribution. Thirdly, a high-resolution time-of-flight aerosol mass spectrometer (HR-ToF-AMS) was used in their work, while a C-ToF-AMS with unit-mass resolution was used in this study. The higher mass resolution of the HR-ToF-AMS relative to a C-ToFAMS may further reduce the influence of product fragments on $m / z 68$ (or others). Finally, differences in temperature or other reaction conditions between experiments may also have led to differences in the morphology of $\mathrm{CA}$ and subsequent differences in the reactivity of CA.

Given the above discrepancy in the consumption of $m / z 68$, the fragments at $m / z 129$ and 147 were used as tracers in this work. The measured $k_{2}$ of CA utilizing $m / z 129$ and 147 in this study is on the same order of magnitude as that reported in Kessler et al. (2012). However, as shown in Fig. 3c, the consumption of $m / z 87$ is much lower than that of $m / z 129$. The apparent $k_{2}$ of CA based on $m / z 87$ is $(9.9 \pm 0.8) \times 10^{-14} \mathrm{~cm}^{3}$ molecule $\mathrm{s}^{-1} \mathrm{~s}^{-1}$, and the diffusioncorrected $k_{2}$ is $(1.16 \pm 0.09) \times 10^{-13} \mathrm{~cm}^{3}$ molecule ${ }^{-1} \mathrm{~s}^{-1}$. This suggests that the derived rate constant greatly depends upon the size of the tracer fragment, with larger fragments resulting in larger values of $k_{2}$ in this study. This is consistent with previous work investigating the $\mathrm{OH}$ oxidation of triphenyl phosphate (TPhP) (Liu et al., 2014) and ambient biogenic SOA (Slowik et al., 2012). The $k_{2}$ of CA based upon PMF analysis is approximately an order of magnitude larger than the Kessler result measured with the tracer at $m / z 68$, and 4.2 times greater than that calculated based upon $m / z 147$ in this study. The differences in product distributions that may arise between this work and the work of Kessler et al. (2012), consistent with the fact that $m / z 68$ is not consumed in the current study, suggest that the PMF approach was likely required in this work to separate similar product and reactant spectra ultimately caused by lower $\mathrm{OH}$ exposure.

A number of factors may be responsible for the discrepancy between derived rate constants. It has previously been observed that the presence of $\mathrm{O}_{3}$ can inhibit the rate of $\mathrm{OH}$ reaction, perhaps by reacting with $\mathrm{OH}$ radicals or by $\mathrm{O}_{3}$ or intermediate species blocking surface active sites (Renbaum and Smith, 2011). A Langmuir-Hinshelwood mechanism has been observed for the reaction of $\mathrm{O}_{3}$ on organic surfaces (Pöschl, 2005). It has also been demonstrated that a higher concentration of gas-phase reactant often leads to a lower uptake coefficient due to surface saturation (Ma et al., 2010; Li et al., 2002). Differences in $k_{2}$ may also arise from the competition between reaction products and reactants for available $\mathrm{OH}$, or via the blocking or coating of the reactant by products which would require liquid-phase diffusion of $\mathrm{OH}$ to degrade the original $\mathrm{CA}$. In experiments with higher $\mathrm{OH}$ exposures (Kessler et al., 2012) it is possible that significantly more product mass is mixed and/or coated onto the original particle, thus decreasing the perceived $k_{2}$. Different timescales and concentrations of reactants might also lead to different rate constants (Che et al., 2009). Finally, as pointed out above, the differing reaction conditions may have led to a different CA morphology and subsequent differences in the reactivity towards $\mathrm{OH}$. The significant difference between the reported rate constants highlights an important issue in heterogeneous reactions of the atmosphere and in the experiments trying to derive such kinetics. It implies that the 


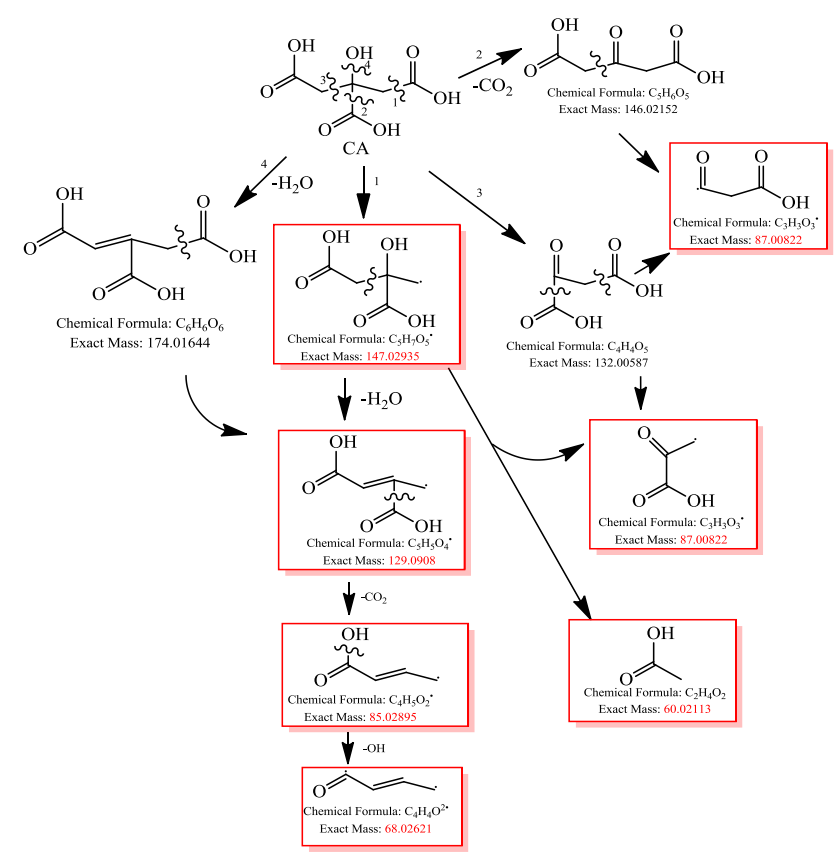

Scheme 1. Possible fragmentation pathways for citric acid.

particle composition and/or morphology as determined by the reaction conditions in the laboratory or the ambient atmosphere will have a large effect on the $\mathrm{OH}$ kinetics.

Citric acid is a hydroxyl-substituted poly carboxyl acid. Scheme 1 summarizes its possible fragmentation pathways. The typical mass peaks including $m / z 147,129,87,85$ and 68 would result from this scheme and were indeed observed. The fragments at $m / z 129,87,85$ and 68 are also likely from CA oxidation products fragments, and hence their signal intensities may be highly influenced by products and/or larger fragments, in particular, when the oxidized products are highly similar to the reactant. In some instances, oxidation products can exhibit similar fragmentation pathways as the reactants. This is likely the case for the smaller fragments of CA. For example, Scheme 2 illustrates the possible fragmentation pathways of 2,3-dihydroxypropane-1,2,3tricarboxylic acid, which is one of the possible products from the $\mathrm{OH}$ oxidation of citric acid in terms of the general chemistry described by Atkinson (1986). As observed in Scheme 2, there are several pathways leading to the fragment at $m / z 87$, implying that the decrease in the signal of $m / z 87$ due to CA oxidation is likely to be compensated by fragments from the oxidation products. In addition, it is also possible to form fragments with the same $\mathrm{m} / z$ as the parent citric acid if the dehydration reaction (the sixth path in Scheme 2) takes place initially. Other possible reaction products might also play similar roles in the fragments. This is highly possible when the product distribution contains products which are structurally similar to the reactant under low oxidant exposure conditions.

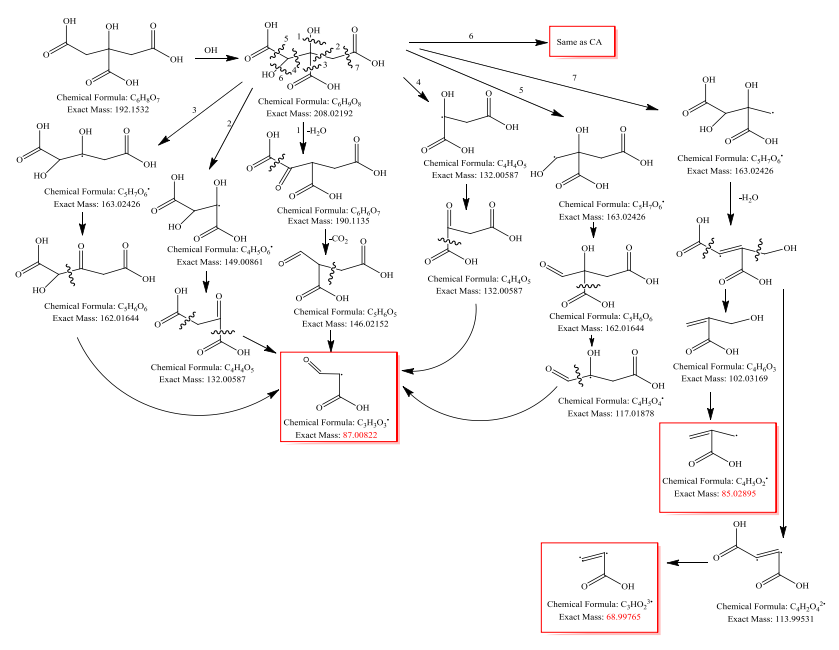

Scheme 2. Possible fragmentation pathways for an oxidation product of citric acid in terms of the general chemistry described by Atkinson (1986).

The current relative rates method based upon PMF analysis was used to reanalyze the heterogeneous oxidation kinetics of three organophosphates (Liu et al., 2014). The $k_{2}$ values for TPhP, tris-1,3-dichloro-2-propyl phosphate (TDCPP) and tris-2-ethylhexyl phosphate (TEHP) utilizing the tracer and PMF approaches are summarized in Table 1. For TPhP, its molecular-ion peak $\left(\mathrm{M}^{+} ; 326\right)$ was chosen as a tracer while the largest detectable fragments, i.e., $m / z 381$ and 323, were chosen for TDCPP $\left(\mathrm{M}^{+} ; 431\right)$ and TEHP $\left(\mathrm{M}^{+} ; 435\right)$, respectively. The typical evolution of the PMF factors of TPhP, TDCPP and TEHP are shown in Supplement Figs. S1-S3. For TPhP, the measured $k_{2}$ values derived by both methods are comparable within the experimental uncertainties, while $k_{2}$ of TDCPP and TEHP based upon PMF analysis is 1.5 and 1.6 times larger than that using the chosen tracers. The good agreement between methods for TPhP is likely due to the fact that the molecular-ion peak $\left(\mathrm{M}^{+}\right)$is measurable for $\mathrm{TPhP}$ with the AMS while it is not observable for TDCPP, TEHP and CA. Therefore, the influence of secondary fragmentation from larger fragments has little influence on the signal of $\mathrm{M}^{+}$for TPhP. These results also demonstrate that a substantial underestimation of rate constants could result when a non-molecular-ion tracer is used to monitor the particlephase concentration of organic matter with UMR-AMS for heterogeneous kinetic studies. The discrepancy between the tracer- and PMF-based methods for other compounds will depend upon a number of factors including structure of products, $\mathrm{OH}$ exposure level, particle morphology and organic species competing $\mathrm{OH}$ reactions. 
Table 1. Comparison of the measured $k_{2}$ values utilizing PMF and select $m / z$ tracers, for organophosphate compounds and CA.

\begin{tabular}{lc|ccc|cc}
\hline OA & Mean & \multicolumn{2}{|c|}{$k_{2}\left(10^{12}\right) \mathrm{cm}^{3}$ molecules $^{-1} \mathrm{~s}^{-1}$} & $k_{2 \_ \text {PMF }} / k_{2}$ Tracer & $M_{\text {Tracer }} / \mathrm{M}^{+}$ \\
& $k_{\text {r_PMF }}$ & $k_{2, \text { obs_PMF }}$ & $k_{2, t \_P M F}$ & $k_{2, t \_T r a c e r}$ & & \\
\hline TPhP & $1.58 \pm 0.33$ & $1.48 \pm 0.31$ & $1.95 \pm 0.43$ & $2.10 \pm 0.19^{*}$ & 0.9 & $326 / 326$ \\
TDCPP & $1.20 \pm 0.31$ & $1.13 \pm 0.29$ & $1.35 \pm 0.35$ & $0.92 \pm 0.09^{*}$ & 1.5 & $381 / 431$ \\
TEHP & $3.52 \pm 0.65$ & $3.31 \pm 0.61$ & $4.25 \pm 0.78$ & $2.70 \pm 0.63^{*}$ & 1.6 & $323 / 435$ \\
CA & $3.01 \pm 0.27$ & $2.83 \pm 0.25$ & $3.31 \pm 0.29$ & $0.79 \pm 0.06$ & 4.2 & $147 / 192$ \\
\hline
\end{tabular}

* Liu et al. (2014)

\section{Implications and conclusions}

The measured $k_{2}$ for citric acid toward $\mathrm{OH}$ is $(3.31 \pm 0.29) \times 10^{-12} \mathrm{~cm}^{3}$ molecules $\mathrm{s}^{-1}$ at $298 \mathrm{~K}$ and $30 \%$ RH. This value is at least 4.2 times greater than that calculated on the basis of a typical tracer $m / z 147$. Although the tracer and PMF approaches can at times agree (Kroll, 2014) and the tracer and molecular-ion approaches can sometimes agree as well (Smith et al., 2009), our results suggest that the heterogeneous kinetics of OA is underestimated when a non-molecular-ion peak is used as the tracer to measure the particle-phase concentration of OA based on UMR-AMS. In model simulations, the reactive uptake coefficient of $\mathrm{OH}$ or other radicals, which are calculated based upon $k_{2}$, is an important parameter in evaluating the fate of OA during transport. The current results suggest that the lifetime of OA estimated in models due to heterogeneous oxidation might be overestimated for a reaction system where the products are highly similar to the reactant and the kinetic data derived by individual non-molecular $\mathrm{m} / \mathrm{z}$ tracers of OA. The results also suggest that it may be necessary to revisit the kinetic data of other organic aerosol components (and $\mathrm{OH}$ uptake coefficients) which have been derived using the relative rates technique (George et al., 2007; Lambe et al., 2007) based on UMR-AMS. Finally, these results imply that the heterogeneous oxidation of aerosols will be dependent upon a number of factors related to the reaction system, and that a single rate constant for one system cannot be universally applied under all conditions. Future work is thus required to elucidate the chemical and physical parameters which control the $\mathrm{OH}$ heterogeneous reaction kinetics and the associated need to apply PMF for a variety of chemical systems. This may be best accomplished through systematic application of the PMF approach to species with differing mass spectral characteristics, such as linear/branched alkanes, monocarboxylic acids and other oxygenates. As illustrated in this study, the kinetics derived with PMF may differ from that derived with tracer ions, with both based upon EI-AMS approaches. This highlights the usefulness of measurements from CIMS, GC-MS and VUV-AMS for the determination of heterogeneous loss rates since these instruments are more likely to retain the reactant molecular information.

\section{The Supplement related to this article is available online at doi:10.5194/acp-14-9201-2014-supplement.}

Acknowledgements. This research was funded by the Chemicals Management Plan (CMP) and the Clean Air Regulatory Agenda (CARA).

Edited by: Y. Cheng

\section{References}

Allan, J. D., Jimenez, J. L., Williams, P. I., Alfarra, M. R., Bower, K. N., Jayne, J. T., Coe, H., and Worsnop, D. R.: Quantitative sampling using an Aerodyne aerosol mass spectrometer 1. Techniques of data interpretation and error analysis, J. Geophys. Res., 108, 4090, doi:10.1029/2002jd002358, 2003.

Atkinson, R.: Kinetics and Mechanisms of the Gas-Phase Reactions of the Hydroxyl Radical with Organic Compounds under Atmospheric Conditions, Chem. Rev., 85, 69-201, 1986.

Atkinson, R. and Arey, J.: Atmospheric Degradation of Volatile Organic Compounds, Chem. Rev., 103, 4605-4638, 2003.

Cappa, C. D., Che, D. L., Kessler, S. H., Kroll, J. H., and Wilson, K. R.: Variations in organic aerosol optical and hygroscopic properties upon heterogeneous $\mathrm{OH}$ oxidation, J. Geophys. Res., 116, D15204, doi:10.1029/2011jd015918, 2011.

Che, D. L., Smith, J. D., Leone, S. R., Ahmed, M., and Wilson, K. R.: Quantifying the reactive uptake of $\mathrm{OH}$ by organic aerosols in a continuous flow stirred tank reactor, Phys. Chem. Chem. Phys., 11, 7885-7895, doi:10.1039/b904418c, 2009.

Donahue, N. M., Robinson, A. L., Hartz, K. E. H., Sage, A. M., and Weitkamp, E. A.: Competitive oxidation in atmospheric aerosols: The case for relative kinetics, Geophys. Res. Lett., 32, L16805, doi:10.1029/2005g1022893, 2005.

Drewnick, F., Hings, S. S., DeCarlo, P., Jayne, J. T., Gonin, M., Fuhrer, K., Weimer, S., Jimenez, J. L., Demerjian, K. L., Borrmann, S., and Worsnop, D. R.: A New Time-of-Flight Aerosol Mass Spectrometer (TOF-AMS)-Instrument Description and First Field Deployment, Aerosol Sci. Tech., 39, 637-658, 2005.

Fuchs, N. A. and Sutugin, A. G.: Highly Dispersed Aerosols, Butterworth-Heinemann, Newton, MA, p. 891970.

George, I. J. and Abbatt, J. P. D.: Chemical evolution of secondary organic aerosol from $\mathrm{OH}$-initiated heterogeneous oxidation, Atmos. Chem. Phys., 10, 5551-5563, doi:10.5194/acp-10-55512010, 2010. 
George, I. J., Vlasenko, A., Slowik, J. G., Broekhuizen, K., and Abbatt, J. P. D.: Heterogeneous oxidation of saturated organic aerosols by hydroxyl radicals: uptake kinetics, condensed-phase products, and particle size change, Atmos. Chem. Phys., 7, 41874201, doi:10.5194/acp-7-4187-2007, 2007.

Hearn, J. D. and Smith, G. D.: A mixed-phase relative rates technique for measuring aerosol reaction kinetics, Geophys. Res. Lett., 33, L17805, doi:10.1029/2006gl026963, 2006.

Huisman, A. J., Krieger, U. K., Zuend, A., Marcolli, C., and Peter, T.: Vapor pressures of substituted polycarboxylic acids are much lower than previously reported, Atmos. Chem. Phys., 13, 66476662, doi:10.5194/acp-13-6647-2013, 2013.

Isaacman, G., Chan, A. W. H., Nah, T., Worton, D. R., Ruehl, C. R., Wilson, K. R., and Goldstein, A. H.: Heterogeneous $\mathrm{OH}$ Oxidation of Motor Oil Particles Causes Selective Depletion of Branched and Less Cyclic Hydrocarbons, Environ. Sci. Technol., 46, 10632-10640, doi:10.1021/es302768a, 2012.

Jacobson, M. Z.: Fundamentals of Atmospheric Modeling, Cambridge University Press, Cambridge , p. 813, 2005.

Jayne, J. T., Leard, D. C., Zhang, X., Davidovits, P., Smith, K. A., Kolb, C. E., and Worsnop, D. R.: Development of an Aerosol Mass Spectrometer for Size and Composition Analysis of Submicron Particles, Aerosol Sci. Tech., 33, 49-70, 2000.

Kessler, S. H., Smith, J. D., Che, D. L., Worsnop, D. R., Wilson, K. R., and Kroll, J. H.: Chemical Sinks of Organic Aerosol: Kinetics and Products of the Heterogeneous Oxidation of Erythritol and Levoglucosan, Environ. Sci. Technol., 44, 7005-7010, doi:10.1021/es101465m, 2010.

Kessler, S. H., Nah, T., Daumit, K. E., Smith, J. D., Leone, S. R., Kolb, C. E., Worsnop, D. R., Wilson, K. R., and Kroll, J. H.: OH-Initiated Heterogeneous Aging of Highly Oxidized Organic Aerosol, J. Phys. Chem. A, 116, 6358-6365, doi:10.1021/jp212131m, 2012.

Kolb, C. E., Cox, R. A., Abbatt, J. P. D., Ammann, M., Davis, E. J., Donaldson, D. J., Garrett, B. C., George, C., Griffiths, P. T., Hanson, D. R., Kulmala, M., McFiggans, G., Pöschl, U., Riipinen, I., Rossi, M. J., Rudich, Y., Wagner, P. E., Winkler, P. M., Worsnop, D. R., and O'Dowd, C. D.: An overview of current issues in the uptake of atmospheric trace gases by aerosols and clouds, Atmos. Chem. Phys., 10, 10561-10605, doi:10.5194/acp-1010561-2010, 2010.

Kroll, J. H. and Seinfeld, J. H.: Chemistry of secondary organic aerosol: Formation and evolution of low-volatility organics in the atmosphere, Atmos. Environ., 42, 3593-3624, 2008.

Lambe, A. T., Zhang, J. Y., Sage, A. M., and Donahue, N. M.: Controlled $\mathrm{OH}$ radical production via ozone-alkene reactions for use in aerosol aging studies, Environ. Sci. Technol., 41, 2357-2363, doi:10.1021/es061878e, 2007.

Lambe, A. T., Miracolo, M. A., Hennigan, C. J., Robinson, A. L., and Donahue, N. M.: Effective Rate Constants and Uptake Coefficients for the Reactions of Organic Molecular Markers (nAlkanes, Hopanes, and Steranes) in Motor Oil and Diesel Primary Organic Aerosols with Hydroxyl Radicals, Environ. Sci. Technol., 43, 8794-8800, doi:10.1021/es901745h, 2009.

Li, P., Al-Abadleh, H. A., and Grassian, V. H.: Measuring heterogeneous uptake coefficients of gases on solid particle surfaces with a Knudsen Cell reactor: complications due to surface saturation and gas diffusion into underlying layers., J. Phys. Chem. A., 106, 1210-1219, 2002.
Liggio, J., Li, S. M., Vlasenko, A., Sjostedt, S., Chang, R., Shantz, N., Abbatt, J., Slowik, J. G., Bottenheim, J. W., Brickell, P. C., Stroud, C., and Leaitch, W. R.: Primary and secondary organic aerosols in urban air masses intercepted at a rural site, J. Geophys. Res.-Atmos., 115, D21305, doi:10.1029/2010jd014426, 2010.

Liu, C., Zhang, P., Wang, Y., Yang, B., and Shu, J.: Heterogeneous Reactions of Particulate Methoxyphenols with $\mathrm{NO}_{3}$ Radicals: Kinetics, Products, and Mechanisms, Environ. Sci. Technol., 46, 13262-13269, 2012.

Liu, Y., Liggio, J., Harner, T., Jantunen, L., Shoeib, M., and Li, S.-M.: Heterogeneous $\mathrm{OH}$ initiated oxidation: A possible explanation for the persistence of organophosphate flame retardants in air, Environ. Sci. Technol., 48, 1041-1048, 2014.

Ma, J., Liu, Y., and He, H.: Degradation kinetics of anthracene by ozone on mineral oxides, Atmos. Environ. , 44, 4446-4453, 2010.

McNeill, V. F., Wolfe, G. M., and Thornton, J. A.: The Oxidation of Oleate in Submicron Aqueous Salt Aerosols: Evidence of a Surface Process, J. Phys. Chem. A, 111, 1073-1083, 2007.

McNeill, V. F., Yatavelli, R. L. N., Thornton, J. A., Stipe, C. B., and Landgrebe, O.: Heterogeneous $\mathrm{OH}$ oxidation of palmitic acid in single component and internally mixed aerosol particles: vaporization and the role of particle phase, Atmos. Chem. Phys., 8, 5465-5476, doi:10.5194/acp-8-5465-2008, 2008.

Norris, G. and Vedantham, R.: EPA positive matrix factorization (PMF) 3.0 fundamentals \& user guide, U.S. Environmental Protection Agency, www.epa.gov (last access: 9 August 2013), 2008.

Paatero, P.: Least squares formulation of robust non - negative factor analysis, Chemometr. Intell. Lab., 37, 23-35, doi:10.1016/S0169-7439(96)00044-5, 1997.

Paatero, P. and Hopke, P. K.: Discarding or downweighting highnoise variables in factor analytic models, Anal. Chim. Acta, 490, 277-289, 2003.

Paatero, P. and Tapper, U.: Positive matrix factorization: a nonnegative factor model with optimal utilization of error estimates of data values, Environmetrics 5, 111-126, 1994.

Pankow, J. F.: An absorption-model of gas-particle partitioning of organic compounds in the atmosphere, Atmos. Environ., 28, 185-188, 1994.

Pöschl, U.: Atmospheric Aerosols: Composition, Transformation, Climate and Health Effects, Angew. Chem. Int. Edit., 44, 75207540, 2005.

Price, H. C., Murray, B. J., Mattsson, J., O’Sullivan, D., Wilson, T. W., Baustian, K. J., and Benning, L. G.: Quantifying water diffusion in high-viscosity and glassy aqueous solutions using a Raman isotope tracer method, Atmos. Chem. Phys., 14, 3817 3830, doi:10.5194/acp-14-3817-2014, 2014.

Reff, A., Eberly, S. I., and Bhave, P. V.: Receptor modeling of ambient particulate matter data using positive matrix factorization: Review of existing methods, JAPCA J. Air Waste Ma., 57, 146154, 2007.

Renbaum, L. H. and Smith, G. D.: Artifacts in measuring aerosol uptake kinetics: the roles of time, concentration and adsorption, Atmos. Chem. Phys., 11, 6881-6893, doi:10.5194/acp-11-68812011, 2011. 
Sareen, N., Moussa, S. G., and McNeill, V. F.: Photochemical Aging of Light-Absorbing Secondary Organic Aerosol Material, J. Phys. Chem. A, 117, 2987-2996, 2013.

Schwartz, R. E., Russell, L. M., Sjostedt, S. J., Vlasenko, A., Slowik, J. G., Abbatt, J. P. D., Macdonald, A. M., Li, S. M., Liggio, J., Toom-Sauntry, D., and Leaitch, W. R.: Biogenic oxidized organic functional groups in aerosol particles from a mountain forest site and their similarities to laboratory chamber products, Atmos. Chem. Phys., 10, 5075-5088, doi:10.5194/acp-10-50752010, 2010.

Slowik, J. G., Wong, J. P. S., and Abbatt, J. P. D.: Real-time, controlled $\mathrm{OH}$-initiated oxidation of biogenic secondary organic aerosol, Atmos. Chem. Phys., 12, 9775-9790, doi:10.5194/acp12-9775-2012, 2012.

Smith, J. D., Kroll, J. H., Cappa, C. D., Che, D. L., Liu, C. L., Ahmed, M., Leone, S. R., Worsnop, D. R., and Wilson, K. R.: The heterogeneous reaction of hydroxyl radicals with submicron squalane particles: a model system for understanding the oxidative aging of ambient aerosols, Atmos. Chem. Phys., 9, 3209-3222, doi:10.5194/acp-9-3209-2009, 2009.

Song, Y., Zhang, Y., Xie, S., Zeng, L., Zheng, M., Salmon, L. G., Shao, M., and Slanina, S.: Source apportionment of PM2.5 in Beijing by positive matrix factorization, Atmos. Environ., 40, 1526-1537, 2006.

Ulbrich, I. M., Canagaratna, M. R., Zhang, Q., Worsnop, D. R., and Jimenez, J. L.: Interpretation of organic components from Positive Matrix Factorization of aerosol mass spectrometric data, Atmos. Chem. Phys., 9, 2891-2918, doi:10.5194/acp-9-2891-2009, 2009.

Viana, M., Kuhlbusch, T. A. J., Querol, X., Alastuey, A., Harrison, R. M., Hopke, P. K., Winiwarter, W., Vallius, A., Szidat, S., Prevot, A. S. H., Hueglin, C., Bloemen, H., Wahlin, P., Vecchi, R., Miranda, A. I., Kasper-Giebl, A., Maenhaut, W., and Hitzenberger, R.: Source apportionment of particulate matter in Europe: A review of methods and results, J. Aerosol. Sci., 39, 827-849, doi:10.1016/j.jaerosci.2008.05.007, 2008.
Weitkamp, E. A., Hartz, K. E. H., Sage, A. M., Donahue, N. M., and Robinson, A. L.: Laboratory measurements of the heterogeneous oxidation of condensed-phase organic molecular makers for meat cooking emissions, Environ. Sci. Technol., 42, 5177 5182, 2008a.

Weitkamp, E. A., Lambe, A. T., Donahue, N. M., and Robinson, A. L.: Laboratory Measurements of the Heterogeneous Oxidation of Condensed-Phase Organic Molecular Makers for Motor Vehicle Exhaust, Environ. Sci. Technol., 42, 7950-7956, doi:10.1021/es800745x, 2008b.

Widmann, J. F. and Davis, E. J.: Mathematical models of the uptake of $\mathrm{ClONO}_{2}$ and other gases by atmospheric aerosols, J. Aerosol. Sci., 28, 87-106, 1997.

Wilson, K. R., Smith, J. D., Kessler, S. H., and Kroll, J. H.: The statistical evolution of multiple generations of oxidation products in the photochemical aging of chemically reduced organic aerosol, Phys. Chem. Chem. Phys., 14, 1468-1479, doi:10.1039/c1cp22716e, 2012.

Worsnop, D. R., Morris, J. W., Shi, Q., Davidovits, P., and Kolb, C. E.: A chemical kinetic model for reactive transformations of aerosol particles, Geophys. Res. Lett., 29, 1996, doi:10.1029/2002g1015542, 2002.

Yuan, Z. B., Yu, J. Z., Lau, A. K. H., Louie, P. K. K., and Fung, J. C. H.: Application of positive matrix factorization in estimating aerosol secondary organic carbon in Hong Kong and its relationship with secondary sulfate, Atmos. Chem. Phys., 6, 25-34, doi:10.5194/acp-6-25-2006, 2006.

Zhang, Q., Jimenez, J., Canagaratna, M., Ulbrich, I., Ng, N., Worsnop, D., and Sun, Y.: Understanding atmospheric organic aerosols via factor analysis of aerosol mass spectrometry: a review, Anal. Bioanal. Chem., 401, 3045-3067, doi:10.1007/s00216-011-5355-y, 2011. 